\title{
CROSS-NATIVITY PARTNERING \& POLITICAL PARTICIPATION: THE EFFECT OF PARTNER'S IMMIGRATION BACKGROUND ON VOTING ACROSS IMMIGRANT GENERATIONS
}

\author{
Hansini Munasinghe \\ Department of Sociology \& Criminology \\ University of Iowa \\ hansini-munasinghe@uiowa.edu
}

\section{Abstract:}

Research on cross-nativity partnering - relationships between immigrants and non-immigrants - has mainly focused on socioeconomic determinants and outcomes of these unions, and their sociopolitical consequences remain underexplored. Extrapolating existing research reveals how cross-nativity relationships may serve as conduits of resources, knowledge, and connections that facilitate political participation; as spaces of political resocialization, bringing together partners with different experiences and understandings of citizenship; and, alternatively, as a selection mechanism whereby immigrant integration results in cross-nativity relationships among those more likely to participate in politics. Using data from the Current Population Survey (CPS) and linking information about married and cohabiting couples, this study assesses whether cross-nativity partnering is associated with voting. Logistic regression models predicting voting using respondents' and their partners' immigrant generation indicate two broad findings. First, having a second or third+ generation partner is positively associated with voting, consistent with theoretical expectations that US-born partners provide resources or signal selection. Second, and more surprisingly, there is small but significant variation in voting among the third+ generation based on their partner's immigrant generation. This indicates inadequacies in theorizing US-born partners solely as providers, and is more consistent with political resocialization. Importantly, this finding challenges theoretical and empirical assumptions in immigration research about the third+ generation as a static baseline. Overall, this study contributes to expanding scholarly focus beyond the individual to the role of relationships, in particular of spouses and cohabiting partners, in integrating immigrants into political life, and, more broadly, in shaping and contextualizing interactions between the state and its citizens and subjects.

Version Date: February $12^{\text {th }}, 2021$ 


\section{CROSS-NATIVITY PARTNERING \& POLITICAL PARTICIPATION: THE EFFECT OF PARTNER'S IMMIGRATION BACKGROUND ON VOTING ACROSS IMMIGRANT GENERATIONS}

\section{INTRODUCTION}

Sociologists have long studied intermarriage - marriages that form across social groups - as signs of blurring boundaries, changing attitudes, and shifting demographics (Foner and Foner 2015; Lichter, Qian, and Tumin 2015; Qian and Lichter 2007, 2011). Cross-nativity marriage represents a particular type of intermarriage, one that crosses nativity lines or immigrant backgrounds. Early immigration scholars conceptualized cross-nativity marriage as a marker of assimilation, and understood it as a final step in the process of immigrants becoming indistinguishably mixed with the wider population (Park and Burgess 1921; Gordon 1964; (Alba and Foner 2015)). Over the last half century, as immigrants and their descendants became one of the fastest growing portions of the US population, cross-nativity partnering - marital or romantic relationships between people of immigrant and non-immigrant backgrounds - have also grown more common (Rodríguez-García 2015; Stevens, Ishizawa, and Escandell 2012). Signaling a wider shift research away from assimilation theory towards immigrant integration - the process of immigrants gaining socioeconomic opportunities and inclusion in key institutions, such as education, and the labor market (Alba and Foner 2015)-, recent research on cross-nativity partnering has largely focused on socioeconomic outcomes and demographic trends (Meng and Gregory 2005; Qian and Lichter 2001). While previous research on cccrossnativity has mainly focused on socioeconomic determinants and outcomes of these unions (Furtado and Song 2015; Meng and Gregory 2005), their sociopolitical consequences remain underexplored.

An important exception to this is Boyd and Couture-Carron (2015), who argue that the same mechanisms resulting in socioeconomic gains for immigrant partners in cross-nativity relationships also facilitate their greater participation in civic and political life. They posit that cross-nativity partnering increases political participation among immigrant partners by providing them with resources, knowledge, and connections needed for participation; and, alternatively, that cross-nativity relationships represent a selection mechanism, where immigrants who are more integrated into the host society overall may be more likely to partner with non-immigrants and also participate in politics. Using Canadian data, they demonstrate variation in political participation, including in voting and in the number of political activities, based on immigrant generation and whether the partner is foreign-born or Canadian-born. In particular, they find that among first generation respondents, those with foreign-born partners are less likely to participate, whereas those with Canadian-born partners are just as likely to 
participate, in comparison to third+ generation respondents with Canadian-born partners. Among the second generation and the third+ generation, they find no significant differences between having a foreign-born or Canadian-born partner. These findings provide evidence that cross-nativity partnering is associated with political participation, specifically, with a boost in participation for first generation immigrants. (Boyd and Couture-Carron 2015).

Another theoretical connection emerges from broader research, primarily from qualitative work that closely examines the lived experiences and perceptions of couples in mixed status cross-nativity relationships (Hart and Besselsen 2020; López 2015), and informed by research on policy-feedback, and relational approaches to political inequality, and critical migration studies (Bruch and Soss 2018; White et al. 2008). Rather than viewing the cross-nativity relationship as a one-way exchange, where the immigrant partner has a deficit that must be filled by the other US-born partner's resources, this theoretical approach understands the cross-nativity relationships as a shared space of political (re)socialization, where upon encountering and sharing lived experiences with someone from a different immigrant background, a different political knowledgebase and identity, and a different relationship to the state, both partners may experience changes in their attitudes and behaviors around politics. This also shifts from assumptions of immigrant deficits in political participation, also provides more room for examining political knowledge and skills immigrant partners may share within the cross-nativity relationship.

These potential connections between cross-nativity partnering and political participation highlight the need for further analysis. This is especially important in the US context, where cross-nativity relationships have historically and contemporarily served as both a sociolegal means of inclusion and exclusion in citizenship in ways that intersect with gender, race, and class (Glenn 2009). For instance, as a result of the Expatriation Act of 1907 US citizen women who married non-citizens lost their citizenship, but this law did not affect men who married non-citizens. Today, following the Immigration and Nationality Act of 1965, US immigration policies prioritize family-based immigration, giving spouses of US citizens the highest priority and one of the fastest routes to citizenship. However, these family-based policies have come under scrutiny in recent years, eliciting racialized fears of chain-migration and proposals to move from family- to skill-based migration policies. Further, pathways to cross-nativity partnerships involve policies and institutions in ways that are gendered, racialized, and selective on educational attainment (Stevens et al. 2012). This contentious history and current policy climate highlight the importance of understanding the political implications of cross-nativity partnering.

This paper extends this line of research on cross-nativity partnering and political participation in the US context. Specifically, this analysis pursues two research 
questions: (1) How does partner's immigrant generation affect the respondent's ${ }^{1}$ political participation? (2) How does the effect of partner's immigrant generation on the respondent's political participation vary across respondent's immigrant generation (interaction effect between respondent's and partner's immigrant generation)? The analysis uses data from the Current Population Survey (CPS), including linked information on married and cohabiting couples, and on voting in general and presidential elections (2000-2018), a key measure of political participation. A key challenge to empirically examining cross-nativity partnering in the US is data availability, given that few existing data sources collect information about both partners' immigration backgrounds. This study overcomes this challenge by utilizing the CPS survey design to link married and cohabiting couples, including detailed information about their own and their parents' birthplaces. This allows for comparisons across three immigrant generation groups - first generation (born outside the US), second generation (born in the US to at least one foreign-born parent), and third+ generation (born in the US to USborn parents). Differentiating by generation, rather than birthplace or immigrantdescent alone, more accurately captures the complexities in the experiences of immigrants (Rumbaut 2004). Cross-nativity partnering is captured as pairings across these immigrant generations, resulting in nine pairing types in total as shown in Table 1.

Two broad findings emerge from these results: First, having a second or third+ generation partner has a positive effect on voting, and this is particularly important for first generation respondents for whom having a a second or third+ generation partner eliminates a gap in voting. This is consistent with theoretical explanations that US-born partners provide resources that immigrants may lack or that having a US-born partner signals a selection effect based on the immigrant partners' overall integration into US society (Boyd and Couture-Carron 2015). Second, and more surprisingly, there is small but significant variation in voting among the third+ generation based on their partners' immigrant generation. While these differences are small, they indicate inadequacies in theorizing USborn partners solely as providers of resources and selection effects as based only on the immigrant partner's successful integration, because these theoretical explanations cannot account for or explain any changes or variation among the third+ generation (Boyd and Couture-Carron 2015). Instead, this finding is more consistent with a relational conceptualization of cross-nativity relationships that allows both partners to potentially experience political resocialization (López 2015). Alternatively, it may indicate an unaccounted for selection or mediation effect based on either the third+ generation partner or both partners. Finally, this variation among the third+ generation also challenges theoretical and empirical assumptions in immigration research that treat the third+ generation as a static baseline against which immigrants are to be compared against.

1 "Respondent" refers to the person identified as the "Head of the Household" in the survey. 
Empirically, this paper contributes a detailed and expansive analysis of crossnativity partnering and voting across two decades of data. It achieves a significant leap in studying cross-nativity partnering in the US by overcoming data limitations utilizing the CPS survey design to link married and cohabiting partners and information about their immigrant backgrounds. It is important to note that because this data is cross-sectional, the results cannot test whether these associations are causal or selection effects. However, the results provide insights on proposed theoretical connections between cross-nativity patterning and political participation, and identify issue for future research. Theoretically, this paper contributes an overview and discussion of these proposed theoretical connections, adding a relational approach to those emerging from the immigrant integration framework. This paper also raises questions about assumptions in existing theories that treat the third+ generation as a static baseline, and highlights the importance of theoretical and methodological approaches that account for and capture both immigrant and non-immigrant partners' experiences in the relationship and in political behaviors. Overall, this study contributes to expanding scholarly focus beyond the individual, to the role of relationships, in particular of spouses and romantic partners, in understanding immigrant political integration, and, more broadly, in shaping and contextualizing interactions between the state and its citizens and subjects.

\section{Political Participation and Voting as Immigrant Political Integration}

An extensive literature has documented patterns in political participation among immigrants, finding that overall, immigrants, especially first generation immigrants, tend to have lower levels of political participation than the wider population (Bass and Casper 2001; Bloemraad 2006; Ramakrishnan and Espenshade 2001; Tran 2017). While political participation encompasses all political activities (such as engaging in conversations about politics, contacting representatives, signing petitions, attending political meetings, and participating in marches or protests), this study focuses on voting, including in general and presidential elections ${ }^{2}$. Comparing voting by immigrant generations shows similar gaps, with first generation immigrants less likely to vote than second and third+ generations, but these patterns vary somewhat by factors such as race and ethnicity, age, and gender (National Academies of Sciences, Engineering, and Medicine 2015; (Bass and Casper 2001; Jones-Correa 1998)). However, using voting as a measure of political participation has several limitations. The naturalization or citizenship requirement poses a significant barrier for first

\footnotetext{
2 While other measures of political participation have been included in CPS Supplements, they are only available for certain years. For example, "took part in a march, rally, protest, or demonstration", "discussing politics with friends or family", and "contacted a public official" were included in 2008-2011, 2013, and 2017; and "attended any group/organization meeting", "took part in a march, rally, protest, or demonstration", and "attended a meeting where political issues are discussed" were only included in 2008.
} 
generation immigrants, and is estimated to account for the majority of the gap in voting among the foreign-born (National Academies of Sciences, Engineering, and Medicine 2015; (Bloemraad 2006)). Immigrants with more resources in terms of income, education, and language fluency are more likely to naturalize (Aptekar 2014; Bloemraad 2006; Jones-Correa 2001). Voter registration as well as finally casting your ballot also pose additional barriers that contribute to lower participation among immigrants (Ramakrishnan 2006; Verba et al. 1993).

\section{Proposed Theoretical Explanations Linking Cross-Nativity Partnering \& Political Participation}

This section briefly summarizes proposed theoretical explanations and expected findings from each. While this study does not aim to untangle these proposed theoretical connections and cannot ascertain casualty with the cross-sectional data at hand, findings can indicate preliminary evidence for or against proposed theoretical explanations and inform future research directions.

Partner as Provider: By extrapolating the theoretical links in research on socioeconomic outcomes to political participation, cross-nativity relationships can be understood as conduits of politically-relevant relevant resources, knowledge, and connections that immigrant partners lack. A partner who has been in the US for more generations can provide these resources, and thereby, increase participation of the immigrant partner. This perspective can also be understood as "partner as teacher" or "partner as facilitator" (Boyd and Couture-Carron 2015). Importantly, this explanation predicts that cross-nativity partnering will result in increased political participation for the immigrant partner, but that the "provider", "teacher", or "facilitator" will not experience any changes.

Selection on Immigrant Integration: An alternative explanation stemming from research on socioeconomic outcomes holds that cross-nativity relationship merely signal a selection mechanism, whereby immigrants who are generally more integrated into US society, will form cross-nativity relationships and also be more likely to participate in politics. Taking background characteristics known to be associated with cross-nativity partnering and political participation into account can narrow this possibility, but with cross-sectional data this cannot ascertain causality. This explanation implies that integration may occur prior to relationship formation. Importantly, this explanation also predicts that any association between cross-nativity partnering and political participation will only be observed for immigrant partner, signifying their successful integration.

Political Re-Socialization: This approach views cross-nativity relationships as a shared space of political (re)socialization, where two people from different immigrant backgrounds, with different understandings of political participation, 
and different relationships to the state may influence each other's worldviews and political attitudes and behaviors. Importantly, this theoretical approach anticipates variation in political participation based on partner's immigrant generation for both partners. However, this approach cannot make definitive predictions about the direction of the effects of cross-nativity partnering on political participation. Rather than assuming immigrants are always deficit in needed resources, this approach leaves room for the possibility that immigrants may bring experiences, perspectives, and connections that - while not directly relevant to practical participation in the US - could motivate and activate their US-born partner's political participation. On the other hand, it is also possible that the experiences immigrant partners bring into cross-nativity relationships - for example, being targeted by discrimination, xenophobia, or restrictive immigration policies - could erode trust in democracy and dampen political participation within the relationship (Heath 2014; López 2020)

Selection or Mediation on Other Observed or Unobserved Measures: The selection mechanism emerging from the research on socioeconomic outcomes and the immigrant integration perspective makes a rather narrow and specific assumption that selection is driven by the immigrant partner's successful integration into US society across socioeconomic and political domains prior or concurrently to the relationship formation. As a result, this explanation predicts that association between cross-nativity partnering and political participation will only be observed among immigrant partners. However, this narrow definition ignores other observed and unobserved factors that may be related to crossnativity partnering and political participation, including neighborhood and other contextual factors; socioeconomic and occupational factors, including military service; and other factors related to assortative mating, like income, higher education, and social networks. While the current study cannot exhaustively examine these possibilities, this highlights the need for further theoretical and empirical examination of cross-nativity partnering outside the narrow confines of immigrant integration framework.

\section{DATA \& METHODS}

This study uses data from the Current Populations Survey (CPS), a nationallyrepresentative survey covering over 65,000 households and their residents every month, conducted by the US Census Bureau and the Bureau of Labor Statistics. The publicly-available, integrated, and harmonized data was obtained via IPUMSCPS (Floods et al. 2020). While the CPS focuses mainly on employment and other socioeconomic measures, several features of this survey make it uniquely suited to examine cross-nativity partnering and political participation. The CPS includes supplemental surveys on special topics, and among these is the Voting and 
Registration Supplement ${ }^{3}$, administered biennially in November of every general and presidential election year. This supplement provides the key measure of political participation for this analysis - whether the respondent voted in the most recent election. Because this supplement focuses on voting, the survey universe is limited to only US citizens who are 18 and older. The current study pools the two most recent decades of data available - that is, all November surveys for general and presidential election years between 2000-2018.

The CPS asks detailed questions about immigration background, including the birthplaces of every person in the household and the birthplaces of their parents, allowing for analysis by immigrant generational status. Another key advantage of the CPS for studying partnering is its survey design. Because the CPS is administered at the household-level, and collects detailed information about every person in the household, it is possible to identify and link people by their relationship to one another, including married as well as cohabitating couples. Utilizing these two features of the CPS - information about each person's immigration background and the ability to linking people in marital and cohabiting relationships - creates a dataset that can be used to examine crossnativity partnering. Given the limited sources of nationally-representative data on immigrants (Duncan and Trejo 2015; Tran 2018), and the rarity of questions about their spouses and cohabiting partners, this data makes a significant contribution in empirically examining cross-nativity partnering in the US.

However, the CPS also has two significant shortcomings. First, despite the large number of households surveyed every month, the data does not allow for disaggregated analysis of immigrant generations across ethnic groups or countries of origin (Tran 2018). This limits the current analysis, and likely overlooks important factors that shape political participation among immigrants, including ethnic identity and political socialization in countries of origin (Ramakrishnan 2006). Second, because this data is effectively cross-sectional ${ }^{4}$, and, results cannot test whether associations observed are causal or selection effects.

The final analytical sample in this study includes 225,635 respondent-and-partner pairs. This dataset was created by merging information about the person identified as the "head of the household" in the survey (hereafter referred to as the "respondent") to information about their spouse or cohabiting partner using the survey year, survey month, and the variable SERIAL, a unique household identifier created by IPUMS-CPS. The resulting individual-level dataset contains information about the respondent, information about their partner, and information about the household overall. In the analysis that follows, the focus is on understanding the respondent's voting behavior using information about

\footnotetext{
3 In analyses not shown here, this study also considers additional measures of political participation from the following supplements: Civic Engagement (available in 2008, 2009, 2010, 2011, 2013, and 2017); and Volunteer (available for 2002-2015, and 2017).

4 The CPS follows the same households for several months, but, because the Voting and Registration Supplement is only administered every two years, the data is effectively cross-sectional.
} 
themselves and their partner. Because this study focuses on partnering and voting, the sample was restricted to respondents who were between ages 20-80 years, eligible to vote, and in a relationship at the time of the survey. Listwise deletion was used for cases with missing data ${ }^{5}$.

Immigrant Generational Status: The main independent variables in this analysis are the immigrant generations of the respondent and their partner. This captures whether their relationship crosses nativity or immigrant generations. For each person, this measure is created using that person's, their mother's, and their father's birthplaces ${ }^{6}$. The majority of respondents were third+ generation (85 percent, $n=192,281)$, and about eight percent were first-generation $(n=17,802)$, and about seven percent were second-generation $(n=15,552)$. Similarly, among partners, the majority were third+ generation (84 percent, $n=189,326)$, about ten percent were first generation $(n=22,799)$, and about six percent were second generation $(n=13,510)$.

Political Participation: The dependent variable used in this analysis to capture political participation is a dichotomous measure of whether the respondent voted in the most recent general or presidential election (coded yes $=1$ and no=0). Overall, 71 percent of respondents in the sample reported voting.

Control Variables: The analysis includes control variables for socioeconomic and demographic characteristics of the respondent, couple-level characteristics, and the survey year. Gender of the respondent is controlled using a dichotomous variable, where identifying as a man is the reference category. Race of the respondent is captured using a five-category variable created by combining survey questions about race and Hispanic/Latino ethnicity: (1) white, no Latino ethnicity; (2) Black, no Latino ethnicity; (3) Asian, no Latino ethnicity; (4) other, including multiracial, American Indian/Aleut/Eskimo, and Hawaiian/Pacific Islander, no Latino ethnicity; (5) and Latino, regardless of race. Two measures of socioeconomic status are included - family income and respondent's educational attainment. Annual family income (income of all persons above age 15 related to the head of household) is recoded into three categories - "low income" (under $\$ 5000-\$ 34,999$ ), "medium income" (\$35,000-\$74,999), and "high income" (\$75,000-\$150,000 and over), and medium income is treated as the reference category. Highest level of educational attainment of the respondent is recoded so that $1=$ "less than high school", 2 = "high school diploma", 3 = "some college", and $4=$ "college degree or higher", where $\mathrm{x}$ is treated as the refence category. Age, measured as a continuous variable, is also included as a control. Using information about the relationship between the respondent and their partner, a dichotomous variable married was created (where cohabiting is the refence category). To disentangle the effects of interracial partnering from cross-nativity partnering, a dichotomous measure of

\footnotetext{
5 Listwise deletion was used in preliminary analyses for convenience, but this method can produce bias and lead to a significant loss of data (Enders 2010). Therefore, future analyses will address this using multiple imputation.

6 This variable considers those born in outlying US territories; and those born abroad to US parents as foreign-born.
} 
endogamy is included, where 1 indicates that both partners identify in the same racial group.

See Appendix for summary statistics of all variables used in the following analysis.

\section{Analytical Methods:}

This analysis is guided by two research questions: (1) How does partner's immigrant generation affect the respondent's political participation? (2) How does this effect of partner's immigrant generation on the respondent's political participation vary across respondent's immigrant generation (interaction effect)? The analysis proceeds in two stages: First, descriptive statistics are used to provide an overview of patterns in cross-nativity relationships and political participation. Second, regression analysis is used to examine these associations between respondent's and partner's immigrant generation and voting while adjusting for other factors that may be associated with cross-nativity partnering and political participation. To do this, the respondent's voting behavior was predicted using their own immigrant generational status, their partner's immigrant generational status, and the interaction between their own and their partner's immigrant generational status. Control variables included characteristics of the respondent (gender; race; age; family income; educational attainment), couple-level characteristics (married vs. cohabiting; endogamy), and the survey year to account for pooled data. This model is as follows:

$$
\begin{aligned}
\text { voted }=\beta_{0}+ & \beta_{1} \text { gen }_{\text {respondent }}+\beta_{2} \text { gen }_{\text {partner }}+\beta_{3}\left(\text { gen }_{\text {respondent }} * \text { gen }_{\text {partner }}\right) \\
& +\beta_{i} \text { controls }_{i}+\varepsilon_{i}
\end{aligned}
$$

Because voting is a binary variable, it was predicted using generalized linear models (estimated using maximum likelihood and Bernoulli conditional distribution). A logit function, the log of the odds of the probability of voting, was used to convert expected probability into a continuous outcome. All analyses were conducted in Stata 14. In the following section, results are reported in logits and as predicted probabilities for interpretation. 


\section{IMMIGRANT GENERATIONAL STATUS AND CROSS-NATIVITY RELATIONSHIPS}

Table 1 shows the array of relationship types by combining the immigrant generational status of the respondent and their partner, along with the sample sizes and prevalence of each type of pairing. The prevalence of cross-nativity relationship status varied across respondents' generations. Among first and third+ generations, the majority were with partners of their same generational status a majority of first generation respondents (71 percent) were with fellow firstgeneration partners; and the majority of third+ generation respondents (91 percent) were with fellow third+ generation partners. In contrast, the majority of second generation respondents (61 percent) were with third+ generation partners, followed by about 22 percent were with fellow second-generation partners, and about 16 percent were with first generation partners. Therefore, second generation respondents were the most likely to be in a relationship that cross immigrant generational status, with a total of 77 percent either with third+ generation or first generation partners. Among first generation respondents, about 29 percent were in relationships that cross immigrant generational status, with about 6 percent with second generation partners and 23 percent with third + generation partners. The third+ generation was the least likely to be in relationships that cross immigrant generational status, with only about four percent and five percent with first and second generation partners, respectively. Overall, of all relationships, about 13 percent $(n=30,121)$ were cross-nativity relationships between partners with immigrant backgrounds (either first or second generation) and those of the third+ generation.

\section{CROSS-NATIVITY PARTNERING \& POLITICAL PARTICIPATION}

Table 2 presents the descriptive overview of the measure of political participation, the percentage of respondents who voted in the most recent election. These results show significant variation in voting behavior by generational status of both the respondent and their partner. Consistent with expectations from previous research (cites), first generation respondents overall were less likely to participate, with about 60 percent reporting that they voted in comparison to about 71 and 72 percent of second and third+ generation respondents, respectively. However, this pattern becomes more nuanced when the immigrant generational statuses of their partners are also taken into consideration. Among both first and second generation respondents, those with second and third+ generation partners (USborn partners) reported higher levels of voting. Comparing first generation respondents by their partner's immigrant generation shows a significant difference in voting behavior - of those with fellow first generation partners, about 56 percent reported voting, whereas of those with second and third+ generation 
partners reported 65 percent and 70 percent, respectively. Similarly, among second generation respondents, the percentage of those who voted increases as their partners' generation increases - of those with first generation partners about 57 percent reported voting, and this increases to about 70 percent for those with fellow second generation partners and to about 75 percent for those with third+ generation partners. These patterns are consistent with theoretical explanations from previous research (Boyd and Couture-Carron 2015) that predict increased political participation among immigrant-background respondents who partner with someone who has been in the US for more generations.

Third+ generation respondents reported small differences in voting based on the generational status of their partner, and in contrast to first and second generation pattern discussed above, the third+ generation did not show a step-wise increase of voting with each increase of partner immigrant generation - instead, among third+ generation respondents, the percentage of those who voted was highest (75 percent) among those with second generation partners. Third+ generation respondents with fellow third+ generation partners reported a slightly lower level of voting at 72 percent, and those with first generation partners at about 71 percent. This shows no significant variation in political participation among the third+ generation, which is also consistent with theoretical explanations from previous research (Boyd and Couture-Carron 2015) that focus on the immigrant partner, and remain agnostic or predict no changes to the political participation of the third+ generation.

Table 3 shows the logistic regression model predicting respondent's voting (yes/no) based on their immigrant generation, their partner's immigrant generation, and the interaction between their own and their partner's immigrant generation, controlling for relevant background characteristics and survey year. Because interaction coefficients in logistic regression models cannot be directly interpreted, these are not shown in results table (Mize 2019; Mustillo, Lizardo, and McVeigh 2018). For clearer interpretation, these interaction effects are shown in Table 4 as the predicted probability of voting for each pairing type by the respondent's and their partner's immigrant generation, holding other variables at the mean, including tests of significance for first and second differences. Figure 1 illustrates these interaction effects, showing the predicted probability of voting for each pairing type by the respondent's and partner's immigrant generation. Two broad findings emerge from these results:

First, having a second generation or third+ generation partner (that is, a US-born partner) has a positive effect on voting. This positive effect of a US-born partner is observed across all respondents, but appears to be particularly important for first generation respondents, for whom a having a US-born partner eliminates a large gap in voting. In comparison to first generation respondents with fellow first generation partners $(\mathrm{Pr}=.578)$, first generation respondents with second 
generation partners have a significantly higher probability of voting $(\mathrm{Pr}=0.700$; diff $=.122, \mathrm{p}<.001)$, as do first generation respondents with third generation partners $(\operatorname{Pr}=0.695$; diff $=-.118, \mathrm{p}<.001)$. This positive effect of a US-born partner also appears for second generation respondents, among whom those with first generation partners have a significantly lower probability of voting $(\mathrm{Pr}=.626)$ than second generation respondents with fellow second generation partners $(\operatorname{Pr}=0.722$; diff $=.096, \mathrm{p}<.001)$ and second generation respondents with third+ generation partners $(\mathrm{Pr}=0.729$; diff $=-.103, \mathrm{p}<.001)$. Consistent with existing theoretical and empirical work, cross-nativity partnering appears to substantively narrow or eliminate gaps in voting among first and second generation respondents.

Interestingly, for both first and second generation respondents, there is no significant difference in partnering with a second generation vs. a third+ generation partner, indicating that partnering with someone born in the US (regardless of their parental immigrant background) seems to be positively associated with voting among both first and second generation respondents ${ }^{7}$. This too seems consistent with theory proposed in previous work - it is possible that for first and second generation respondents, US-born partners provide knowledge, resources, and connections that facilitate voting, or signify a selection mechanism where first and second generation respondents with US-born partners are generally more integrated and more likely to participate. However, not all results can be captured with either of these proposed theoretical connections surprisingly, second generation respondents with first generation partners are significantly less likely to vote than fellow second generation respondents with second generation partners (diff $=.626-.722=-.096, \mathrm{p}<.001$ ) or third generation partners (diff $=.626-.729=-.103, p<.001)$. Because the second generation is USborn, resource-based explanations would predict their role as providers of resources unaffected by their partner's immigrant generation, and selection-based explanations about their first generation partner's successful integration also do not explain why US-born second generation respondents would experience this decline in voting (Boyd and Couture-Carron 2015).

Relatedly, the second interesting finding emerging from these results is that there is small but significant variation in voting among third+ generation respondents based on their partners' immigrant generation. Third+ generation respondents with first generation partners have a significantly lower probability of voting $(\mathrm{Pr}=.657)$ than third+ generation respondents with second generation partners $(\mathrm{Pr}=.736$; diff=-.080, $\mathrm{p}<.001)$. Interestingly, third+ generation respondents with fellow third+ generation partners have a significantly lower probability of voting $(\mathrm{Pr}=.722)$ than third + generation respondents with second generation partners $(\operatorname{Pr}=.736$; diff $=.014, \mathrm{p}<.01)$. While these differences are small, they indicate limitations of theoretical connections proposed - theorizing the role of third+ generation partners only as providers of resources and conceptualizing selection

\footnotetext{
7 In supplementary analyses (not shown), I combine second and third+ generations (US-born) and find similar results.
} 
effects only as the immigrant partner's successful integration - that cannot account for or explain any changes or variation among the third+ generation (Boyd and Couture-Carron 2015). This variation also challenges theoretical and empirical assumptions in immigration research that treat the third+ generation as a static baseline against which immigrants are to be compared against. The practice of comparing immigrants and their descendants to "natives" or the third+ generation is a practice that has been criticized by critical migration ssscholars for assuming that immigrants and their descendants begin from a deficit or a problem; and that the third+ generation is a static and stable baseline against which immigrants are to be compared against.

Finally, control variables predict voting consistent with expectations from previous research - women are significantly more likely to vote than men; in comparison to white respondents, Black respondents are more likely to vote, while other racial groups, especially Asians, are significantly less likely to vote; in comparison to high school higher levels of education are associated with a higher likelihood of voting; and age is positively associated with voting. Similarly, for couple-level characteristics, marriage (in comparison to cohabitation) and endogamy (in comparison to partners with different racial identities) are both positively associated with voting.

These findings of lower probabilities of voting among US-born second and third+ generation with first generation partners may be better explained with a relational conceptualization of cross-nativity relationships that allows both partners, including those who are US-born, to potentially experience political resocialization (López 2015b). Alternatively, it may indicate an unaccounted for selection or mediation effects based on either the characteristics of either partner or both partners. For example, do cross-nativity couples that include a first generation partner live in neighborhoods or work in occupations that that make voting less likely? Overall, these variations in the probability of voting among the third+ generation and among the second generation with first generation partners highlight the importance of theoretical and empirical work that further examines how non-immigrants' political behaviors and attitudes change through their relationships with immigrants. 


\section{DISCUSSION \& FUTURE DIRECTIONS}

The main goal of this paper is to examine cross-nativity partnering and political participation in the US context. Previous research indicates that cross-nativity relationships may serve as a conduit of resources, knowledge, and skills that immigrants are lacking, and thereby facilitate increased participation; as a shared space of political (re)socialization that influence both partners' political behaviors; and/or a selection effect whereby immigrants who are more generally more integrated, may also be more likely to form cross-nativity relationships and participate in politics. Informed by these theoretical possibilities, this paper tackles two research questions - (1) how does partner's immigrant generation affects the respondent's voting behavior, and (2) how this effect of partner's immigrant generation vary across respondent's immigrant generation (interaction effect)? Using data from the Current Population Survey (CPS), including linked information about the immigrant backgrounds of married and cohabiting couples, this study examines the effect of the respondent's and their partner's immigrant generation on voting in general and presidential elections between 2000-2018.

Overall, this study makes several contributions. This analysis utilizes features of the IPUMS-CPS survey design to link married and cohabiting couples, and identify their immigrant generations represents a a significant leap in researching cross-nativity partnering in the US. The data and analysis presented here provide a thorough and, to my knowledge, unprecedented insight into the relationship between cross-nativity partnering and voting in the US over the last two decades. Importantly, this study includes both married and cohabiting couples, which is important given that cohabitation is on the rise. The results from this analysis indicate that, overall, having a second generation or third+ generation partner is associated with an increased probability of voting. This effect appears to be particular important for first generation respondents, for whom having a US-born eliminates a significant gap in voting. This finding is largely consistent with proposed explanations from previous research. Second, these results found small but significant variation in voting among the third+ generation. This highlights limitations in theoretical explanations that focus only on improved outcomes for the immigrant partner - including seeing cross-nativity relationships as conduits of resources or as a selection mechanism based on immigrant partner's successful integration - and, therefore, cannot explain why the third+ generation partner would experience any changes. Similarly, second generation respondents with first generation partners experience a lower probability of voting than second generation respondents with second or third+ generation partners, and this cannot be explained by theoretical mechanisms that are agnostic about changes or variation among the US-born.

These findings further indicate that the immigrant-deficit model, where immigrants are understood to suffer gaps that can be fulfilled by US-born 
partners, may not adequately capture how cross-nativity partnering shapes political participation. It is possible that, as hypothesized in the resocialization mechanism, that the US-born experience changes to their political behaviors and attitudes following their close interactions with foreign-born partners. However, it is also possible that though other selections mechanisms third+ generation individuals who form relationships with first generation immigrants are somehow different on observed or unobserved variables (such as their socioeconomic status, the characteristics of the neighborhoods they live in etc.). Importantly, this finding also challenges theoretical and empirical assumptions in immigration research about the third+ generation as a static baseline against which immigrants' success is measured against. While the current analysis cannot discern causality, the results provide evidence that the effects of cross-nativity partnering on political participation are not limited to immigrants, highlighting the need for future theoretical and empirical research that seeks to understand sociopolitical implications of cross-nativity partnering, not foreign-born only immigrants, but also on their US-born partners. Overall, this study contributes to expanding scholarly focus beyond the individual to the role of relationships, in particular of spouses and cohabiting partners, in integrating immigrants into political life, and, more broadly, in shaping and contextualizing interactions between the state and its citizens and subjects.

However, there are also limitations and unanswered questions in the current analysis that need to be addressed in future work. Particularly important in this regard is better data capturing details of relationships and families, immigrant background, and important outcomes beyond voting, and data that follows individuals and families over time and captures relationship formation and dissolution, which would allow for closer examination of causality. While voting is a very direct measure of political participation, it limits the analysis to citizens only and does not reflect the range of political activities immigrants engage in. Therefore, future studies should consider a broader range of political and civic participation outcomes. Another question that requires further analysis is the role of gender in this association and possible mechanisms. For instance, in the mechanisms where the partner serves as a provider of resources or as a teacher of knowledge and skills, gender roles and doing gender will likely shape these interactions and their outcomes. Cross-nativity relationships may also simultaneously cross racial, ethnic, linguistic, and religious barriers, which further complicate research on this topic. The current analysis included controls for the respondent's race and whether the relationship was between partners of the same race (endogamy). However, this leaves important questions unanswered about the experiences of immigrants incorporating into racialized and unequal political systems. In addition, future research should also consider immigrants' length of time in the US and their country of origin, specifically, the level of democracy in that country, matters. Relatedly, better data is needed to understand timing of relationship formation, especially whether couples partnered before 
coming to the US. These data limitations highlight the need for future data collection and research on cross-nativity partnering.

\section{REFERENCES}

Alba, Richard, and Nancy Foner. 2015. "Mixed Unions and Immigrant-Group Integration in North America and Western Europe." The ANNALS of the American Academy of Political and Social Science 662(1):38-56. doi: 10.1177/0002716215594611.

Aptekar, Sofya. 2014. "Citizenship Status and Patterns of Inequality in the United States and Canada." Social Science Quarterly 95(2):343-59. doi: https://doi.org/10.1111/ssqu.12018.

Bass, Loretta E., and Lynne M. Casper. 2001. "Differences in Registering and Voting between Native-Born and Naturalized Americans." Population Research and Policy Review 20(6):483-511.

Bloemraad, Irene. 2006. Becoming a Citizen: Incorporating Immigrants and Refugees in the United States and Canada. University of California Press.

Boyd, Monica, and Amanda Couture-Carron. 2015. "Cross-Nativity Partnering and the Political Participation of Immigrant Generations" edited by D. Rodríguez-García. The ANNALS of the American Academy of Political and Social Science 662(1):188-206. doi: 10.1177/0002716215594630.

Bruch, Sarah K., and Joe Soss. 2018. "Schooling as a Formative Political Experience: Authority Relations and the Education of Citizens." Perspectives on Politics 16(1):36-57. doi: $10.1017 / \mathrm{S} 1537592717002195$.

Duncan, Brian, and Stephen J. Trejo. 2015. "Assessing the Socioeconomic Mobility and Integration of U.S. Immigrants and Their Descendants." The ANNALS of the American Academy of Political and Social Science 657(1):108-35. doi: 10.1177/0002716214548396.

Foner, Alba, and Nancy Foner. 2015. Strangers No More: Immigration and the Challenges of Integration in North America and Western Europe. Princeton Press.

Furtado, Delia, and Tao Song. 2015. "Intermarriage and Socioeconomic Integration: Trends in Earnings Premiums among U.S. Immigrants Who Marry Natives." The ANNALS of the American Academy of Political and Social Science 662(1):207-22. doi: $10.1177 / 0002716215594629$.

Glenn, Evelyn Nakano. 2009. Unequal Freedom. Harvard University Press.

Hart, Betty De, and Elles Besselsen. 2020. "Everything Went According to the Rules'. Female Citizen Sponsors' Legal Consciousness, Intimate Citizenship and Family Migration Law.” Identities 0(0):1-19. doi: 10.1080/1070289X.2020.1723310.

Heath, Anthony. 2014. "Introduction: Patterns of Generational Change: Convergent, Reactive or Emergent?" Ethnic and Racial Studies 37(1):1-9. doi: 10.1080/01419870.2014.844845.

Jones-Correa, Michael. 1998. "Different Paths: Gender, Immigration and Political Participation." International Migration Review 32(2):326-49. doi: 10.1177/019791839803200202. 
Jones-Correa, Michael. 2001. "Institutional and Contextual Factors in Immigrant Naturalization and Voting." Citizenship Studies 5(1):41-56. doi: 10.1080/13621020020025187.

Lichter, Daniel T., Zhenchao Qian, and Dmitry Tumin. 2015. "Whom Do Immigrants Marry? Emerging Patterns of Intermarriage and Integration in the United States." The ANNALS of the American Academy of Political and Social Science 662(1):57-78. doi: $10.1177 / 0002716215594614$.

López, Jane Lilly. 2015a. "Impossible Families': Mixed-Citizenship Status Couples and the Law." Law \& Policy 37(1-2):93-118. doi: https://doi.org/10.1111/lapo.12032.

López, Jane Lilly. 2015b. “Impossible Families': Mixed-Citizenship Status Couples and the Law: Impossible Families.” Law \& Policy 37(1-2):93-118. doi: 10.1111/lapo.12032.

López, Jane Lilly. 2020. "Together and Apart: Transnational Life in the US-Mexico Border Region." Journal of Ethnic and Migration Studies 46(1):242-59. doi: 10.1080/1369183X.2018.1523003.

Meng, Xin, and Robert G. Gregory. 2005. "Intermarriage and the Economic Assimilation of Immigrants." Journal of Labor Economics 23(1):135-74. doi: 10.1086/425436.

Mize, Trenton D. 2019. "Best Practices for Estimating, Interpreting, and Presenting Nonlinear Interaction Effects." Sociological Science 6:81-117. doi: 10.15195/v6.a4.

Mustillo, Sarah A., Omar A. Lizardo, and Rory M. McVeigh. 2018. "Editors' Comment: A Few Guidelines for Quantitative Submissions." American Sociological Review 83(6):1281-83. doi: $10.1177 / 0003122418806282$.

Qian, Zhenchao, and Daniel T. Lichter. 2001. "Measuring Marital Assimilation: Intermarriage among Natives and Immigrants." Social Science Research 30(2):289-312. doi: 10.1006/ssre.2000.0699.

Qian, Zhenchao, and Daniel T. Lichter. 2007. "Social Boundaries and Marital Assimilation: Interpreting Trends in Racial and Ethnic Intermarriage." American Sociological Review 72(1):68-94. doi: 10.1177/000312240707200104.

Qian, Zhenchao, and Daniel T. Lichter. 2011. "Changing Patterns of Interracial Marriage in a Multiracial Society.” Journal of Marriage and Family 73(5):1065-84. doi: 10.1111/j.17413737.2011.00866.x.

Ramakrishnan, S. Karthick. 2006. Democracy in Immigrant America: Changing Demographics and Political Participation. 1st edition. Stanford University Press.

Ramakrishnan, S. Karthick, and Thomas J. Espenshade. 2001. "Immigrant Incorporation and Political Participation in the United States.” The International Migration Review 35(3):870-909.

Rodríguez-García, Dan. 2015. "Intermarriage and Integration Revisited: International Experiences and Cross-Disciplinary Approaches" edited by D. Rodríguez-García. The ANNALS of the American Academy of Political and Social Science 662(1):8-36. doi: 10.1177/0002716215601397.

Rumbaut, Ruben G. 2004. "Ages, Life Stages, and Generational Cohorts: Decomposing the Immigrant First and Second Generations in the United States." International Migration Review 38(3):1160-1205. doi: 10.1111/j.1747-7379.2004.tb00232.x. 
Stevens, Gillian, Hiromi Ishizawa, and Xavier Escandell. 2012. "Marrying into the American Population: Pathways into Cross-Nativity Marriages." International Migration Review 46(3):740-59. doi: https://doi.org/10.1111/j.1747-7379.2012.00903.x.

Tran, Van C. 2017. "Beyond the Ballot Box: Age-at-Arrival, Civic Institutions and Political Participation among Latinos." Journal of Ethnic and Migration Studies 43(5):766-90. doi: 10.1080/1369183X.2016.1194745.

Tran, Van C. 2018. "Social Mobility across Immigrant Generations: Recent Evidence and Future Data Requirements." The ANNALS of the American Academy of Political and Social Science 677(1):105-18. doi: 10.1177/0002716218762725.

Verba, Sidney, Kay Lehman Schlozman, Henry Brady, and Norman H. Nie. 1993. "Race, Ethnicity and Political Resources: Participation in the United States." British Journal of Political Science 23(4):453-97.

White, Stephen, Neil Nevitte, André Blais, Elisabeth Gidengil, and Patrick Fournier. 2008. "The Political Resocialization of Immigrants: Resistance or Lifelong Learning?" Political Research Quarterly 61(2):268-81. doi: 10.1177/1065912908314713.

Sarah Flood, Miriam King, Renae Rodgers, Steven Ruggles and J. Robert Warren. Integrated Public Use Microdata Series, Current Population Survey: Version 8.0 [dataset]. Minneapolis, MN: IPUMS, 2020. https://doi.org/10.18128/D030.V8.0

National Academies of Sciences, Engineering, and Medicine 2015. The Integration of Immigrants into American Society. Washington, DC: The National Academies Press. https://doi.org/10.17226/21746. 


\section{TABLES \& FIGURES}

Table 1: Sample Size and Prevalence of Each Pairing Type by Immigrant Generational Status of the Respondent and their Partner.

\begin{tabular}{|clrr|}
\hline \multirow{2}{*}{ Respondent } & \multicolumn{1}{c}{ Partner } & Sample Size & $\begin{array}{r}\text { Prevalence of } \\
\text { Pairing Type }\end{array}$ \\
\hline \multirow{3}{*}{ First Generation } & First Generation & 12,658 & $71.10 \%$ \\
& Second Generation & 1,091 & $6.13 \%$ \\
& Third Generation & 4,053 & $22.77 \%$ \\
\cline { 2 - 4 } & & Total $=17,802$ & $100.00 \%$ \\
\hline \multirow{3}{*}{ Second Generation } & & \\
& First Generation & 2,507 & $16.12 \%$ \\
& Second Generation & 3,515 & $22.60 \%$ \\
& Third Generation & 9,530 & $61.28 \%$ \\
\cline { 2 - 4 } & & & $100.00 \%$ \\
\hline \multirow{3}{*}{ Third Generation } & Total $=15,552$ & $3.97 \%$ \\
& First Generation & 7,634 & $4.63 \%$ \\
& Second Generation & 8,904 & $91.40 \%$ \\
\cline { 2 - 4 } & Third Generation & 175,743 & $100.00 \%$ \\
\cline { 2 - 4 } & & \multicolumn{3}{c}{ Total $=192,281$} \\
\hline
\end{tabular}

Source: CPS data (2000-2018) 
Table 2: Percentage voted, by respondent's and their partners' immigrant generation status.

\begin{tabular}{|c|c|c|c|c|}
\hline & \multirow{2}{*}{$\begin{array}{c}\% \text { Voted } \\
\text { Overall }\end{array}$} & \multicolumn{3}{|c|}{ \% Voted by Partner's Immigrant Generation } \\
\hline & & 1st Gen Partner & 2nd Gen Partner & $3^{\text {rd }}$ Gen Partner \\
\hline 1st Gen Respondent & 59.55 & 55.66 & 65.44 & 70.12 \\
\hline $2^{\text {nd }}$ Gen Respondent & 70.94 & 56.76 & 69.90 & 75.06 \\
\hline $3^{\text {rd }}$ Gen Respondent & 72.19 & 70.79 & 75.06 & 72.11 \\
\hline
\end{tabular}

Source: CPS data, $\mathrm{N}=225,635$ 
Table 3: Logistic regression results predicting voting (in logits), using respondent's generational status and their partner's generational status, controlling for characteristics of the respondent and the couple. $\mathrm{N}=225,635$

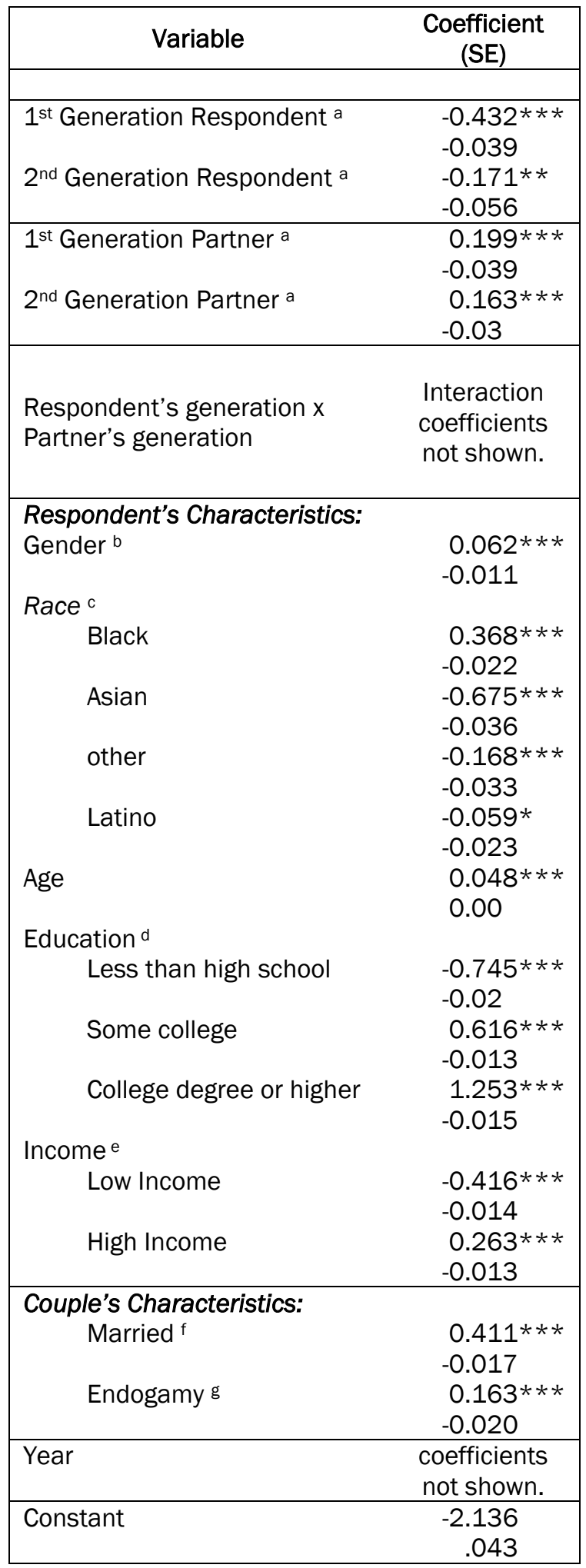

Standard errors in parentheses, $* * *$ $p<0.001, * * p<0.01, * p<0.05$

\section{Reference categories:}

a - in comparison to $3^{\text {rd }}+$ generation

$\mathrm{b}$ - in comparison to men

c - in comparison to white

d - in comparison to high school

e - in comparison to medium income

$f$ - in comparison to cohabiting

$\mathrm{g}$ - in comparison to different race couple

$$
\begin{array}{ll}
\text { Number of obs } & =225,635 \\
\text { LR chi2 }(30) & =46539.93 \\
\text { Prob }>\text { chi2 } & =0.0000 \\
\text { Log likelihood } & =-112374.58 \\
\text { Pseudo R2 } & =0.1716
\end{array}
$$


Figure 1: Predicted probability of voting by respondent's generational status and partner's generational status, controlling for respondent's socioeconomic and demographic characteristics and couple's characteristics.

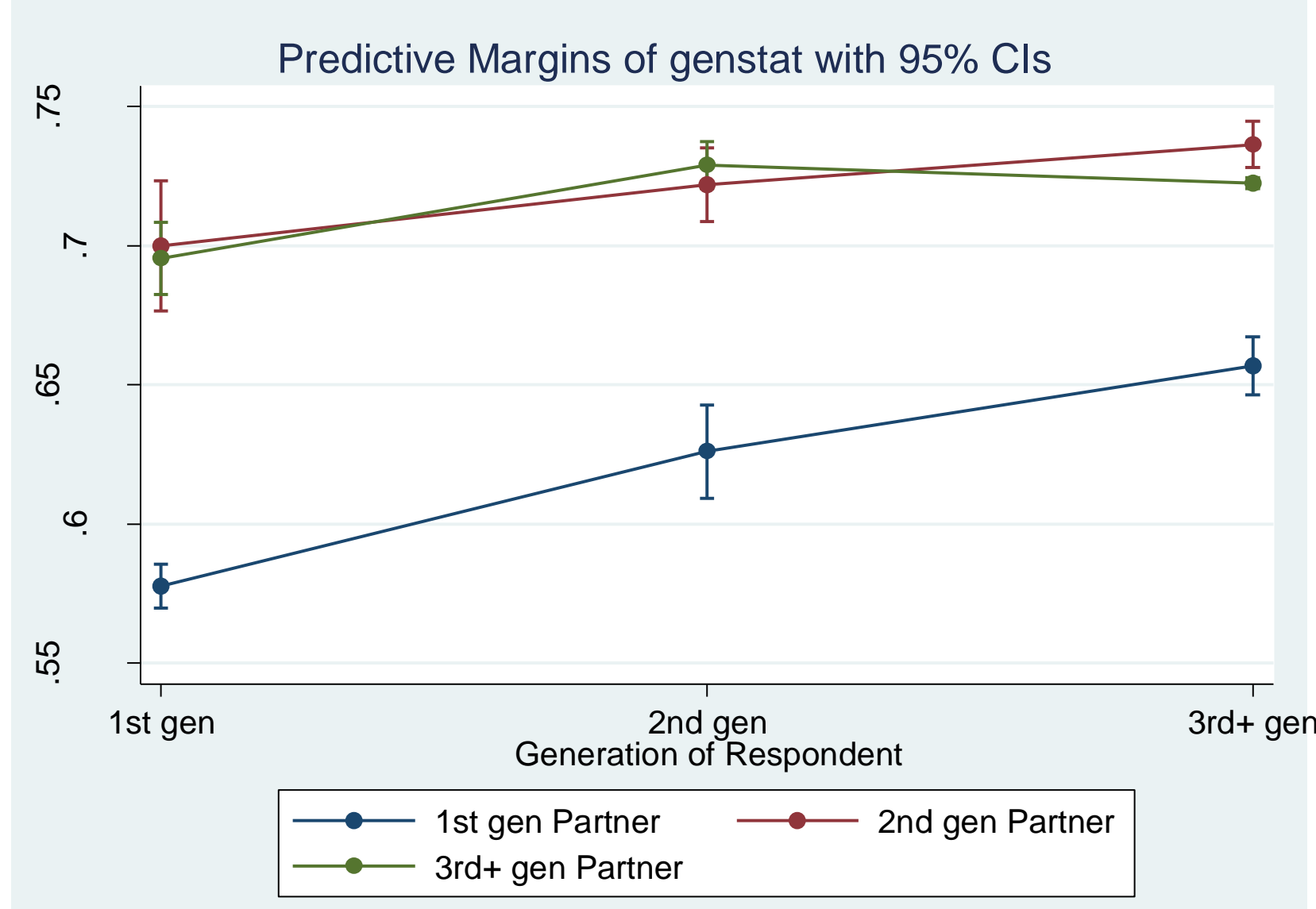


Table 4: Probability of voting by the respondent's and their partner's immigrant generation, average marginal effects showing differences in probability of voting between partnering types, and contrasts showing differences in probability of voting between partnering types that are significantly different across respondents' generations (second differences). $(\mathrm{N}=225,635)$.

\begin{tabular}{|c|c|c|c|c|c|c|}
\hline & \multicolumn{3}{|c|}{ Predicted Probability of Voting } & \multicolumn{3}{|c|}{$\begin{array}{l}\text { Difference in Probability between Partnering Types } \\
\text { (Average Marginal Effects) }\end{array}$} \\
\hline & $\begin{array}{l}\text { 1st Gen } \\
\text { Partner }\end{array}$ & $\begin{array}{l}\text { 2nd Gen } \\
\text { Partner }\end{array}$ & $\begin{array}{l}\text { 3rd+ Gen } \\
\text { Partner }\end{array}$ & $\begin{array}{l}\text { 1st vs. 2nd Gen } \\
\text { Partner }\end{array}$ & $\begin{array}{l}\text { 1st vs. 3rd Gen } \\
\text { Partner }\end{array}$ & $\begin{array}{l}\text { 2nd vs. 3rd Gen } \\
\text { Partner }\end{array}$ \\
\hline $\begin{array}{l}\text { 1st Gen } \\
\text { Respondent }\end{array}$ & $\begin{array}{l}.578 \\
(.004)\end{array}$ & $\begin{array}{l}.700 \\
(.012)\end{array}$ & $\begin{array}{l}.695 \\
(.007)\end{array}$ & $\begin{aligned} & .578-.700= \\
&-.122 * * *\end{aligned}$ & $\begin{aligned} & .578-.695= \\
&-.118 * * *\end{aligned}$ & $\begin{array}{l}.700-.695= \\
.004 \text { n.s. }\end{array}$ \\
\hline $\begin{array}{l}\text { 2nd Gen } \\
\text { Respondent }\end{array}$ & $\begin{array}{l}.626 \\
(.009)\end{array}$ & $\begin{array}{l}.722 \\
(.007)\end{array}$ & $\begin{array}{l}.729 \\
(.004)\end{array}$ & $\begin{aligned} & .626-.722= \\
&-.096 * * *\end{aligned}$ & $\begin{aligned} & .626-.729= \\
&-.103 * * *\end{aligned}$ & $\begin{aligned} & .729-.729= \\
&-.007 \text { n.s. }\end{aligned}$ \\
\hline \multirow[t]{4}{*}{$\begin{array}{l}\text { 3rd+ Gen } \\
\text { Respondent }\end{array}$} & $\begin{array}{l}.657 \\
(.005)\end{array}$ & $\begin{array}{l}.736 \\
(.004)\end{array}$ & $\begin{array}{l}.722 \\
(.001)\end{array}$ & $\begin{aligned} .657-.736 & = \\
& -.080 * * *\end{aligned}$ & $\begin{aligned} .657-.722 & = \\
& -.066 * * *\end{aligned}$ & $\begin{aligned} .736-.722= \\
.014 * *\end{aligned}$ \\
\hline & & & & \multicolumn{3}{|c|}{ Contrasts (Second Differences) } \\
\hline & & & & $\begin{array}{l}\text { 1st Gen }>\text { 3rd Gen } \\
\begin{aligned}(-.122)-(-.080)= \\
-0.043 * *\end{aligned}\end{array}$ & $\begin{array}{l}\text { 1st Gen }>\text { 3rd Gen } \\
\begin{aligned}(-.118)- & (-.066)= \\
& -0.052 * * *\end{aligned}\end{array}$ & $\begin{array}{c}\text { 3rd Gen }>2 n d \text { Gen } \\
(-.007)-(.014)= \\
-0.021 *\end{array}$ \\
\hline & & & & & $\begin{array}{c}\text { 2nd Gen }>\text { 3rd Gen } \\
\begin{aligned}(-.103)-(-.066)= \\
-0.037 * *\end{aligned}\end{array}$ & \\
\hline
\end{tabular}

Source: Current Population Survey (2000-2018).

$* * * p<.001, * * p<0.01, * p<.05$ two-tailed tests. 